\title{
A meritocracia como fator motivacional na administração pública
}

\author{
Christiano Moritz da Silva ${ }^{1}$, Flavia Luciane Scherer ${ }^{1}$, Aletéia de Moura Carpes $^{1}$
}

\author{
${ }^{1}$ Universidade Federal de Santa Maria. \\ Correspondência: E-mail: flaviascherer@globo.com \\ Av. Roraima, 1000 \\ Santa Maria - RS - Brasil \\ CEP $97105-900$
}

Resumo

A meritocracia é uma ferramenta de gestão de pessoas muito utilizada na iniciativa privada, mas na administração pública encontra certa resistência para sua implantação. Em 2010 o Rio Grande do Sul instituiu a carreira de analista de planejamento, orçamento e gestão na Secretaria de Planejamento, Gestão e Participação Cidadã, visando adotar o sistema de meritocracia na esfera pública estadual. Passados dois anos, foi avaliada a percepção da categoria em relação aos conceitos da meritocracia ao qual estão submetidos. Assim, a pesquisa é norteada pela questão: Qual o grau de motivação dos servidores com o atual plano de carreira meritocrático? Utilizou-se o método de abordagem descritivo, aplicando procedimentos de pesquisa bibliográficos, documentais e de levantamento censitário tipo survey. Foi utilizado o questionário como instrumento para coleta dos dados e um corte-transversal caracterizando a coleta em um só momento. Para a análise e tratamento foram empregados os métodos quantitativo e qualitativo, predominando o primeiro. Verificou-se que o grau de motivação depende mais da forma como o plano de carreira meritocrático é discutido e implementado do que de suas características.

Palavras-chave: meritocracia, administração pública, fator motivacional, percepção, plano de carreira.

Abstract Meritocracy is a tool for managing people much used in private and in public administration, found some resistance to its implementation. In June 2010, the Rio Grande do Sul appointed a law aiming to adopt the system of meritocracy in the public sphere state. After two years, it is necessary to evaluate the perception of the category in relation to the concepts of meritocracy to which they are subjected. The research is guided by the question: What degree of motivation of the servers with 
the current meritocratic career plan? We used the method of descriptive approach, applying procedures for bibliographic research, documentary and census type survey. We used the questionnaire as a tool for data collection and a cross-section characterizing the collection in a single moment. For the analysis and treatment were employed quantitative and qualitative methods, especially in the former. It was found that the motivation level depends on how the career path meritocratic and implemented is discussed, not of its characteristics.

Keywords: meritocracy, public administration, motivational factor, perception, career plan.

Resumen La meritocracia es una herramienta de gestión que se utiliza en el muy privado, pero en la administración pública se encuentra cierta resistencia a su implementación. En 2010, Rio Grande do Sul estableció la carrera de analista de planificación, presupuesto y gestión en el Departamento de Participación Planificación, Gestión y Participación Ciudadana, con el objetivo de adoptar el sistema de meritocracia en el estado esfera pública. Después de dos años, se evaluó la percepción de la categoría en relación con los conceptos de meritocracia a la que están sometidos. La investigación se guía por la pregunta: ¿Qué grado de motivación de los servidores con el plan de carrera meritocrático actual? Se utilizó el método de aproximación descriptiva, aplicando procedimientos para la investigación bibliográfica, documental y la encuesta tipo censo. Se utilizó el cuestionario como instrumento de recolección de datos y una sección transversal que caracteriza la colección en un solo momento. Para el análisis y el tratamiento se utilizaron métodos cuantitativos y cualitativos, sobre todo en la primera. Se encontró que el nivel de motivación es más dependiente de la forma de la trayectoria de la carrera meritocrática se discute y aplicado encima de sus características.

Palabras-clave: meritocracia, administración pública, factor de motivación, perception, plan de carrera. 


\section{Introdução}

Entre os diversos meios a sua disposição, o Estado tem recursos humanos, servidores e funcionários públicos que tem a função de transformar as vontades e diretrizes de um governo eleito democraticamente pela sociedade, em realidade. Ou seja, transformar intenções de campanha em políticas públicas de efeito, em obras e serviços que atendam as necessidades e anseios da sociedade.

Para que estas transformações ocorram com qualidade, é necessário gerenciar, coordenar e gerir as pessoas nesta direção. A gestão de pessoas procura adequar os interesses da organização, com os interesses dos colaboradores, buscando principalmente motivar as pessoas e aumentar a produtividade. Gerir pessoas é uma tarefa complexa, porém fundamental.

Nos últimos anos, o sistema de meritocracia na administração pública brasileira vem sendo bastante debatido, mas sua utilização ainda restrita a poucas carreiras. Buscando contribuir e trazer novos dados para esta discussão, justificase o presente estudo pelo objetivo de avaliar o grau de motivação dos servidores da Secretaria de Planejamento, Gestão e Participação Cidadã do Estado do Rio Grande do Sul, após a implantação do novo plano de carreira da categoria, em abril de 2010.

O plano de carreira de analistas de planejamento, orçamento e gestão na Secretaria de Planejamento é o primeiro no estado a utilizar os critérios meritocráticos. Passados mais de dois anos de sua implantação, apurar a opinião dos servidores sobre este tema pode trazer contribuições para todos: governo, sociedade e servidores.

O presente estudo está composto pela fundamentação teórica acerca da meritocracia e gestão de pessoas, seguido do método da pesquisa, apresentação e discussão dos resultados e considerações finais.

\section{Compreendendo a meritocracia}

A meritocracia é definida por Barbosa (2003a:12) como um sistema de governo ou outra organização que considera o mérito (aptidão) a razão para se atingir determinada posição. A palavra meritocracia tem origem no latim, mereocracia, significando mereo (merecer, obter) e cracia (sistema).

Para Duarte (2005:365), o conceito de meritocracia pode ser definido como "a fórmula utilizada por organizações, como estímulo profissional, oferecendo recompensas aos seus integrantes que proporcionem melhorias importantes para elas ou para sua clientela". 
Baseando-se nestes autores, pode-se definir conceitualmente que meritocracia é um aglomerado de valores, que estabelece que a regra para a ocupação de posições em uma organização deve ser derivada do mérito de cada um, ou seja, do merecimento por seu desempenho individual.

É um sistema que não considera privilégios (corporativos, hereditários, sociais, etc.) em função da posição social e poder político. Na meritocracia, são recompensados os que demonstrarem talento e competência, seja através da competição ou de atos já realizados.

Na ótica de Barbosa (2003), o principal problema é que no Brasil a meritocracia e a avaliação de desempenho sempre foram questões polêmicas, principalmente porque no país não existe uma ideologia meritocrática estabelecida na sociedade, mas sim de sistemas e discursos meritocráticos. Entre a sociedade brasileira, culturalmente ainda é forte a ideia de que cobrar resultados e, ainda, tentar mensurá-los, é uma atitude autoritária.

Ainda que muitas vezes o tema possa parecer novo, Barddal et al. (2008) remontam à antiguidade os primeiros indícios semelhantes de mecanismos de avaliação e compensação pelo desempenho, mais precisamente na China, onde Confúcio e Han Fei são citados como pensadores que propuseram um sistema próximo ao meritocrático. Também são lembrados Gengis Khan e Napoleão Bonaparte, cada qual utilizou no exército e na vida política de seus Estados, elementos da meritocracia.

\section{Gestão de pessoas}

Fischer (2001) apresenta um conceito básico ao falar de gestão de pessoas, relacionando a importância das relações pessoais para que os objetivos possam ser atendidos:

Em geral considera-se 'gestão' uma ação para a qual há um menor grau de previsibilidade sobre o resultado do processo a ser 'gerido'. Um navio é dirigido, uma empresa é administrada, mas uma relação humana pode, no máximo, ser gerida - isso quando se admite que os dois agentes tem consciência e vontade próprias. Usar o termo 'gestão' pode significar resgatá-lo do caráter humano e sobrepô-lo ao aspecto técnico no âmbito do relacionamento entre pessoas e organização. (Fischer 2001:14).

Na mesma perspectiva, Sovienski e Stigar (2002) apresentam uma diferença conceitual entre recursos humanos e gestão de pessoas. Há décadas que o 
costume era exigir das pessoas apenas a execução de tarefas específicas, sem que o servidor precisasse ter conhecimento do processo completo e das implicações da qualidade de sua execução. Já na atualidade Ihe são atribuídas responsabilidades pelo êxito daquele processo como um todo (metas), exigindo conhecimentos e virtudes mais amplas.

Para França (2009), a avaliação de resultados, na área de gestão de pessoas, refere-se à prática de julgar e contemplar os objetivos atingidos, definidos pela organização, com uso eficiente dos recursos.

A atuação da área de recursos humanos apresenta baixa participação estratégica, por isso atualmente vem se reconstruindo. Devido a este panorama, aumenta a importância de se determinar parâmetros de avaliação para os investimentos realizados na área.

Segundo Dessler (2003:32), a avaliação de desempenho é realizada por três motivos: "traz informações importantes de decisões sobre promoções e reajuste salarial, permite desenvolver planos de correções de deficiências reveladas na avaliação e ainda pode ser útil no planejamento de carreira".

A avaliação fornece a administração informações importante para tomada de decisões administrativas e seus resultados possuem papel importante na motivação dos funcionários, segundo França (2009). O objetivo é também proporcionar o crescimento e desenvolvimento do colaborador, além deste saber como está seu desempenho na função que realiza.

De acordo com França (2009), cada sistema de avaliação possui suas peculiaridades, com pontos fortes e fracos. Para a escolha é necessário observar as necessidades e realizar uma combinação dos sistemas mais adequados.

Dentre os sistemas mais comuns temos a avaliação da experiência, que consiste em solicitar ao avaliador para descrever as principais características do avaliado, suas qualidades e limitações, potenciais e dimensões do comportamento do avaliado.

\section{Método}

A abordagem desta pesquisa pode ser classificada como descritiva. Para Silva e Menezes (2000), este tipo de pesquisa visa descrever as características de determinada população, fenômeno ou o estabelecimento de relações entre variáveis. Envolve-se o uso de técnicas padronizadas de coleta de dados: questionário e observação sistemática.

A pesquisa foi realizada com integrantes da carreira de analista de planejamento, orçamento e gestão (APOG) na Secretaria de Planejamento, Gestão e 
Participação Cidadã. Esta nova carreira foi a primeira a adotar o sistema de meritocracia na administração pública estadual do Rio Grande do Sul.

Foram buscadas percepções e entendimento sobre a natureza geral da questão da motivação por meio da meritocracia, abrindo espaço para a interpretação. Zanella (2009) afirma que esse é um tipo de estudo utilizado em administração pública, já que se presta a descrever as características de um determinado fato ou fenômeno, sem a interferência do pesquisador.

Quanto aos procedimentos técnicos, foi adotada a pesquisa bibliográfica, documental e de levantamento do tipo survey. A pesquisa bibliográfica, de acordo com Gil (1999), é elaborada a partir de materiais já publicados, livros, artigos, periódicos e materiais publicados na internet.

Cervo e Bervian (1983:55) acrescentam que a pesquisa bibliográfica "busca conhecer e analisar as contribuições culturais ou científicas do passado sobre determinado assunto, tema ou problema", assim como no presente estudo, a partir do levantamento de referencial teórico acerca da meritocracia e formas de gestão e motivação de pessoas.

De acordo com Lakatos e Marconi (2007), a pesquisa documental relaciona-se com materiais que ainda não receberam tratamento analítico ou podem ser reformulados, a qual explora documentos escritos ou não escritos, de fontes primárias ou não.

Foram analisados registro e informações verbais junto à entidade sindical da categoria, para verificar e validar sobre o histórico da carreira e junto ao departamento de pessoal, onde foram obtidos dados como o número de servidores concursados que foram nomeados e os que solicitaram exoneração nos últimos quinze anos.

O levantamento do tipo survey, segundo Lakatos e Marconi (2007), envolve a interrogação direta dos indivíduos em que se deseja conhecer melhor o comportamento, atitudes, motivos ou ideias. Babbie (1999) indica a pesquisa survey para medir opiniões, comportamentos, preferências e atitudes de certo conjunto de indivíduos.

Babbie (1999) também relata que a coleta de dados é realizada no mesmo local de realização da pesquisa, comparando com a pesquisa bibliográfica feita por consultas a fontes impressas e que esta coleta é indireta, realizada com muitos respondentes e generaliza seu resultado, ao contrário do estudo de caso, que inclui baixo número de indivíduos.

Por meio de um questionário estruturado, foram aplicadas 19 questões fechadas com escala, para possibilitar uma gradação nas respostas, e uma questão aberta, para proporcionar a expressão de ideias. 
Cinco perguntas serviram para caracterizar o público alvo em relação a: seu tempo de carreira, escolaridade, conhecimento mínimo sobre o assunto meritocracia, sua preferência em relação à promoção por mérito ou antiguidade e a percepção da relevância das funções da Secretaria para a sociedade e demais órgãos públicos.

Outras treze questões abordaram temas abrangendo motivação, desmotivação, qualificação, satisfação e avaliação de desempenho; com a finalidade de apurar a percepção dos analistas em relação a estes aspectos.

As respostas para as questões foram construídas em uma escala do tipo Likert, utilizada frequentemente para questionários de survey (Babbie 1999). Foram colocadas categorias de um (1) a cinco (5), onde um (1) representa o nível mais baixo, agregando resultados como "pouco satisfeito", "não atende", "discordo completamente", "nada motivante", "contribui pouco" e "pouco relevante".

A escala máxima é definida como cinco (5) e representa o nível máximo, agrupando respostas como "muito satisfeito", "atende completamente", "concordo completamente", "extremamente motivante", "contribui muito", "muito relevante" e "muito desmotivante". A escala intermediária representada pelo índice três (3) significa resultados como "indiferente" e "tanto faz".

Por fim, no mesmo questionário, foi disponibilizado um espaço para inserção de texto livre, com o intuito de incentivar a colocação de comentários, opiniões, sugestões, críticas e quaisquer outras observações que o respondente considerase relevante. Este espaço qualitativo revelou-se de grande valia para a pesquisa, visto que propiciou a coleta de relevantes percepções que ajudaram a esclarecer os resultados quantitativos obtidos.

\section{População e procedimento de coleta}

Sendo a carreira de analista de planejamento, orçamento e gestão (APOG), o objeto desta pesquisa e composta por uma população total de 70 pessoas, optouse pelo levantamento censitário, que ocorre quando todas as pessoas de uma população são interrogadas, pois é uma população pequena, ou seja, a amostra significativa teria que ser próxima do número total da população (Lakatos e Marconi 2007).

Quanto ao ponto temporal em que os dados foram coletados, utilizou-se o corte transversal, caracterizado pela coleta dos dados em um só momento.

Quanto ao procedimento de coleta, o questionário auto aplicado foi disponibilizado durante quatro dias na internet utilizando-se a ferramenta Google Docs, e o link para acessar o questionário foi enviado por correio eletrônico aos participantes, acompanhado de um breve texto explicativo. 
No quarto dia pela manhã, foi enviado um novo e-mail com agradecimentos pela grande participação e lembrando aos que ainda não haviam respondido que o instrumento ficaria disponível até o final do dia. Com este movimento, obtiveramse mais algumas participações, totalizando 47 respostas (67\% da população).

\section{Análise e tratamento dos dados}

A presente pesquisa utilizou a técnica quantitativa para dar tratamento aos dados e tratamento qualitativo para a única questão aberta no questionário. Malhotra (2006:154) diz que a "pesquisa qualitativa proporciona melhor visão e compreensão do contexto do problema, enquanto a pesquisa quantitativa procura quantificar os dados em números".

A parte quantitativa procurou medir os sentimentos e percepções dos respondentes, utilizando variáveis ordinais para as respostas por meio da escala Likert de 1 a 5 traduzidas em números com a utilização de percentis.

Segundo Gonçalves e Meirelles (2004), o método quantitativo é indicado nos casos onde é necessário conhecer a extensão do objeto estudado, identificando o nível de conhecimento e opiniões em relação ao problema. As cinco primeiras questões tiveram a utilização de variáveis nominais para melhor caracterização dos respondentes e as demais foram variáveis ordinais.

Para a última questão do questionário, que era aberta e não obrigatória, foi utilizada a técnica qualitativa para análise. Gonçalves e Meirelles (2004) afirmam que na pesquisa qualitativa os dados são de caráter interpretativo, sendo este adequado para estudar valores, percepções e motivações; o método oferece informações mais subjetivas sem preocupação estatística.

\section{Resultados}

O questionário foi disponibilizado para toda a população pesquisada, ficando a participação condicionada à vontade de cada um. Foi utilizada a ferramenta Google Docs para envio e recebimento dos questionários, como já detalhado anteriormente na seção de métodos. Dos 70 questionários enviados, 47 foram respondidos, determinando uma representatividade de $67 \%$.

A pergunta inicial questionava quanto tempo o servidor está na carreira, com a orientação de que contasse o tempo como analista e técnico, quando fosse o caso.

É possível observar que mais de 55\% dos respondentes, ou seja, 26 analistas possuem menos de cinco anos na carreira (Figura 1). Este percentual sobe para 
74\% (37 analistas) quando considerados os analistas com até dez anos de carreira.

Figura 1. Tempo na carreira de técnico e/ou analista. Rio Grande do Sul, 2012.

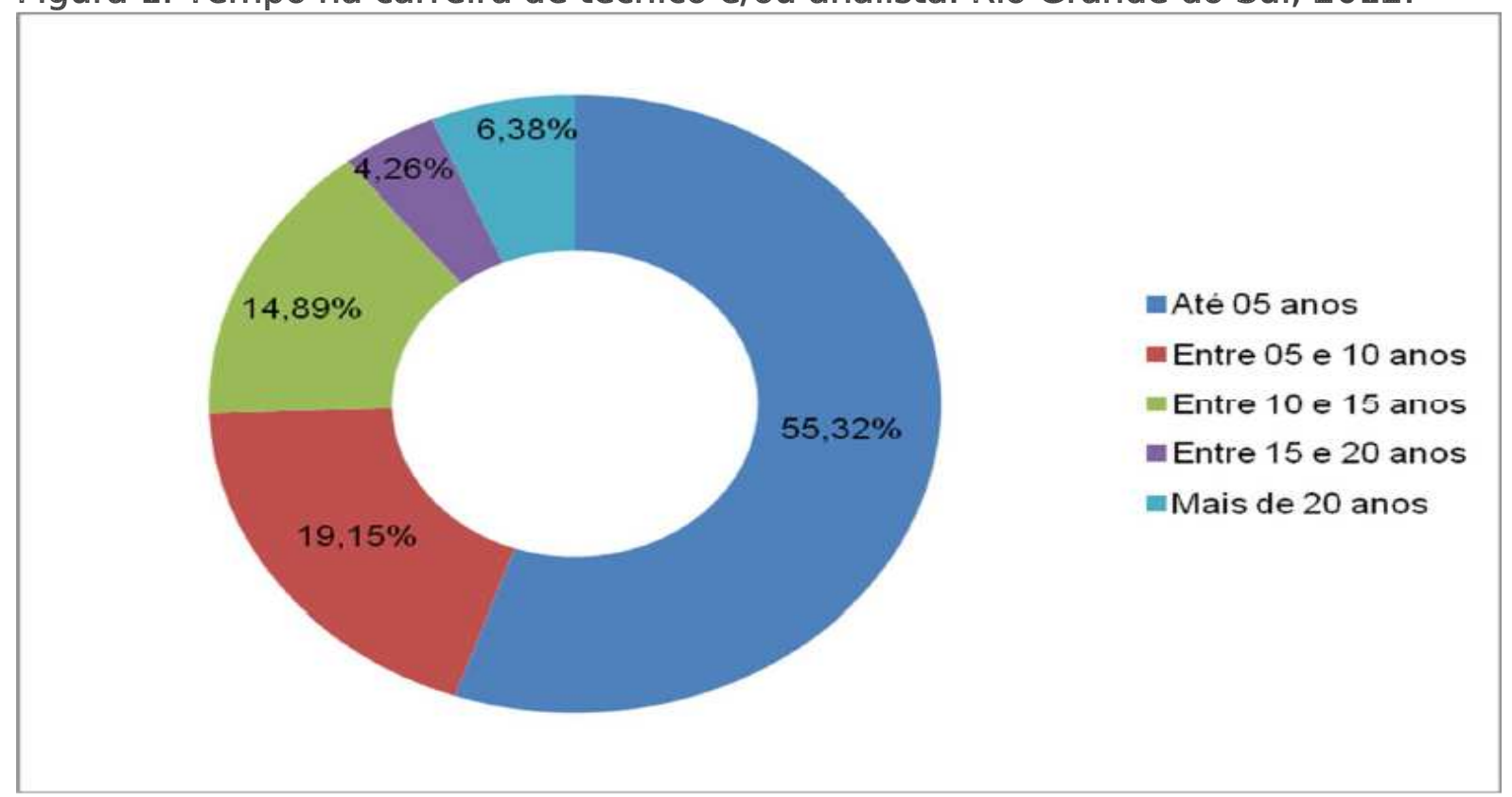

Fonte: Autoria própria.

Em relação ao grau de escolaridade, a pesquisa ratifica que o quadro da SEPLAG é altamente qualificado, com servidores aptos a executarem trabalhos de grande complexidade na sua formulação e que possuem funções estratégicas para o centro de governo (Figura 2).

Os resultados refletem em toda a administração pública estadual e, por consequência, proporcionam inúmeros benefícios para a sociedade gaúcha.

Verifica-se que $78 \%$ dos analistas possuem, no mínimo, uma pós-graduação ou especialização no seu currículo. Constata-se que apenas $21 \%$ (dez analistas) possuem somente a graduação superior (pré-requisito para o cargo). Porém, ressalta-se que este percentual pode ser ainda menor, pois não foram consideradas qualificações atualmente em curso.

Tem-se ainda que 34\% (16 analistas) possuem um título de especialista ou pósgraduado, enquanto que $17 \%$ (oito analistas) possuem mais de um título de especialista ou pós-graduado.

Os respondentes que declararam possuírem título de mestrado também são 17\%, e os que possuem além do mestrado, um título de especialista ou pós-graduado representam 10,6\% (cinco analistas). Nenhum dos respondentes possui titulação acadêmica de doutorado. 
Figura 2. Grau de escolaridade dos servidores de carreira da SEPLAG. Rio Grande do Sul, 2012.

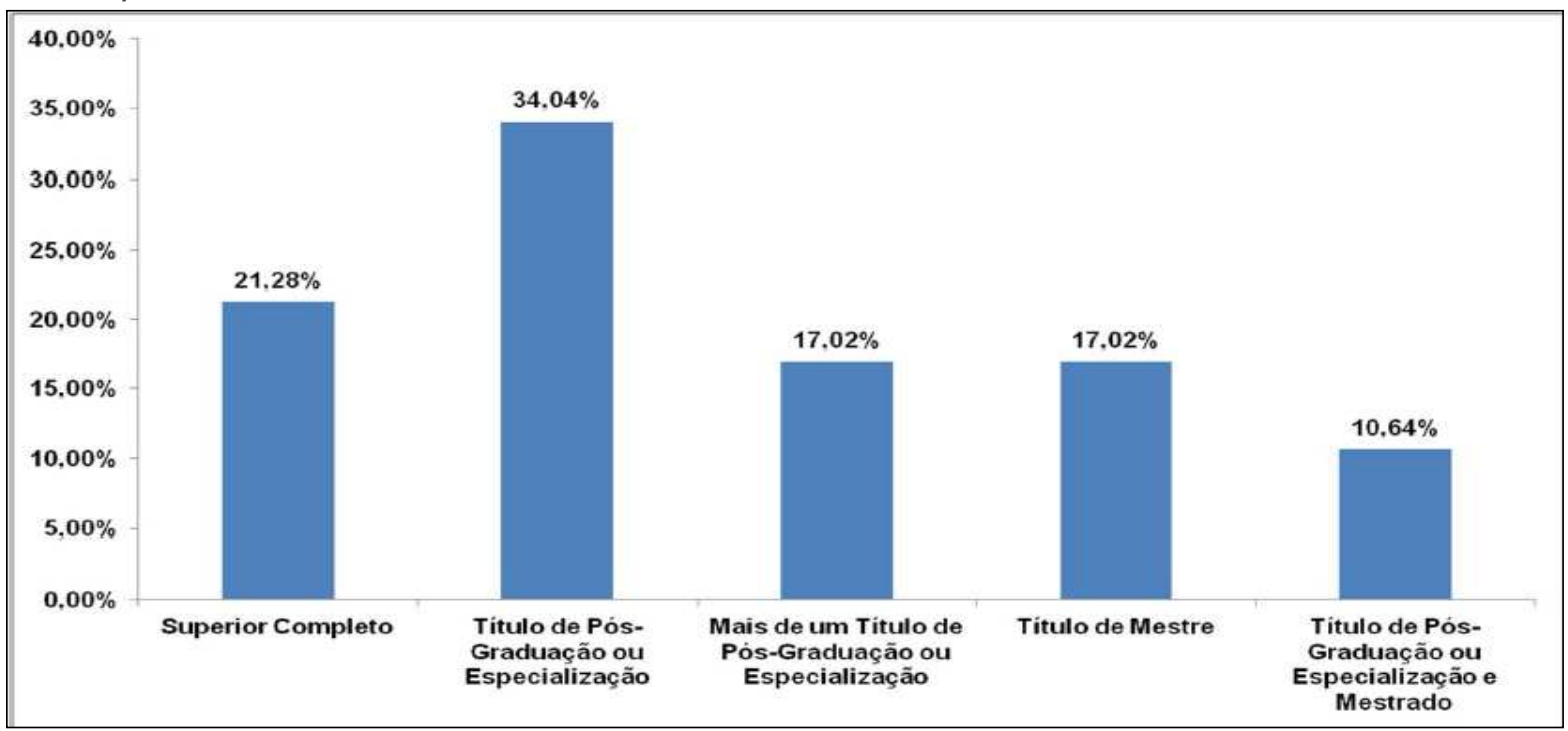

Fonte: Autoria própria.

Os servidores possuem plena consciência da importância que seu trabalho tem para a estrutura administrativa gaúcha e das atividades que a SEPLAG desempenha. 81\% (39 analistas) consideram que estas atividades são relevantes ou muito relevantes. Ninguém citou "pouco relevante" para a questão (Figura 3).

Figura 3. Relevância das funções da Secretaria na ótica dos servidores. Rio Grande do Sul, 2012.

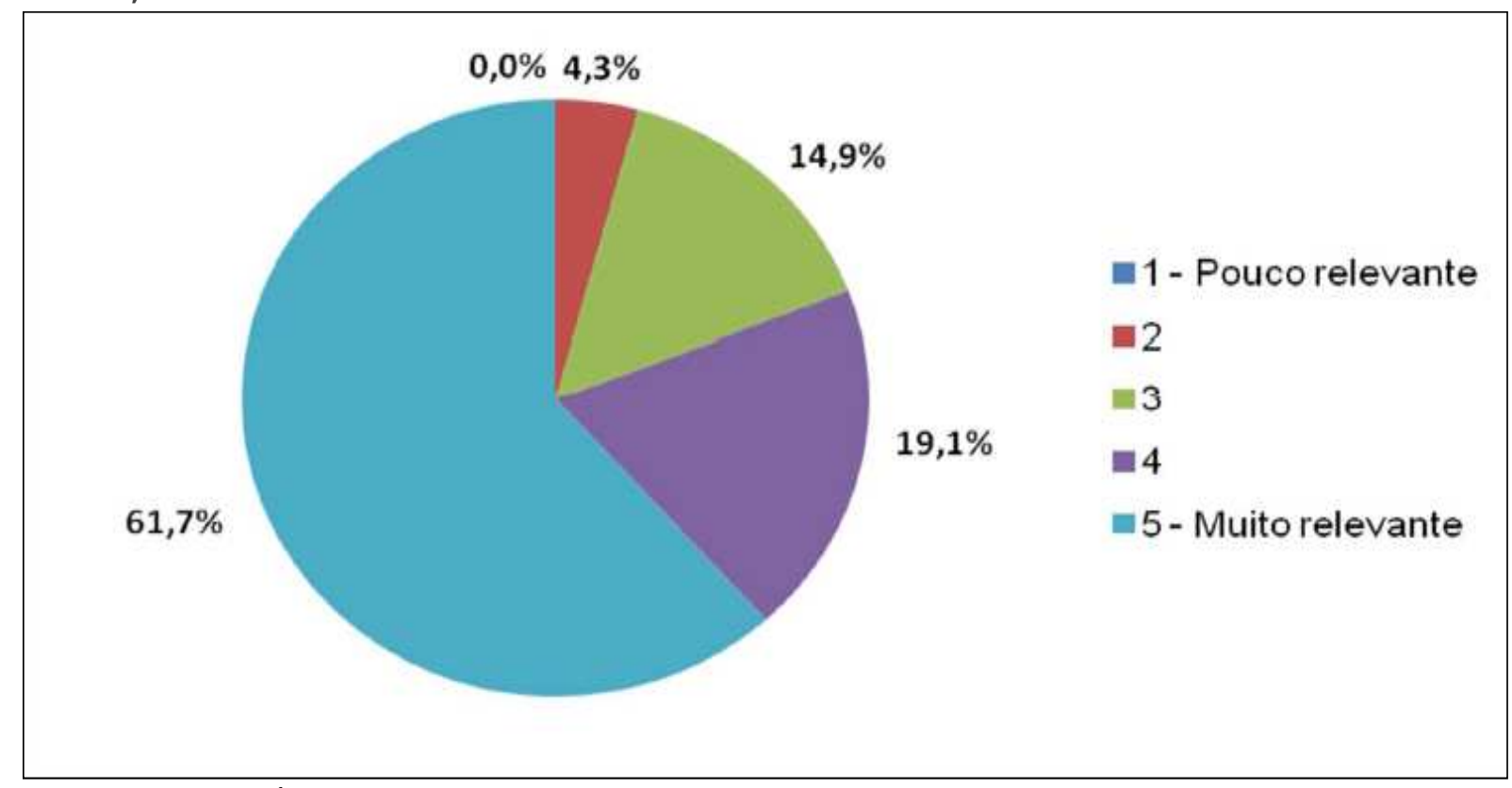

Fonte: Autoria própria. 
Em relação a critérios de promoção e progressão, nenhum analista considera motivante a utilização somente de critérios de antiguidade, sendo o merecimento considerado por todos como um fator motivante e mais justo. Interessante observar que as respostas ficaram divididas, com 23 analistas (48,9\%) sentindose mais motivados com critérios exclusivamente de merecimento e a mesma proporção $(48,9 \%)$ com critérios alternando merecimento e antiguidade (Figura 4).

Figura 4. Preferência por critérios de promoção e progressão. Rio Grande do Sul, 2012.

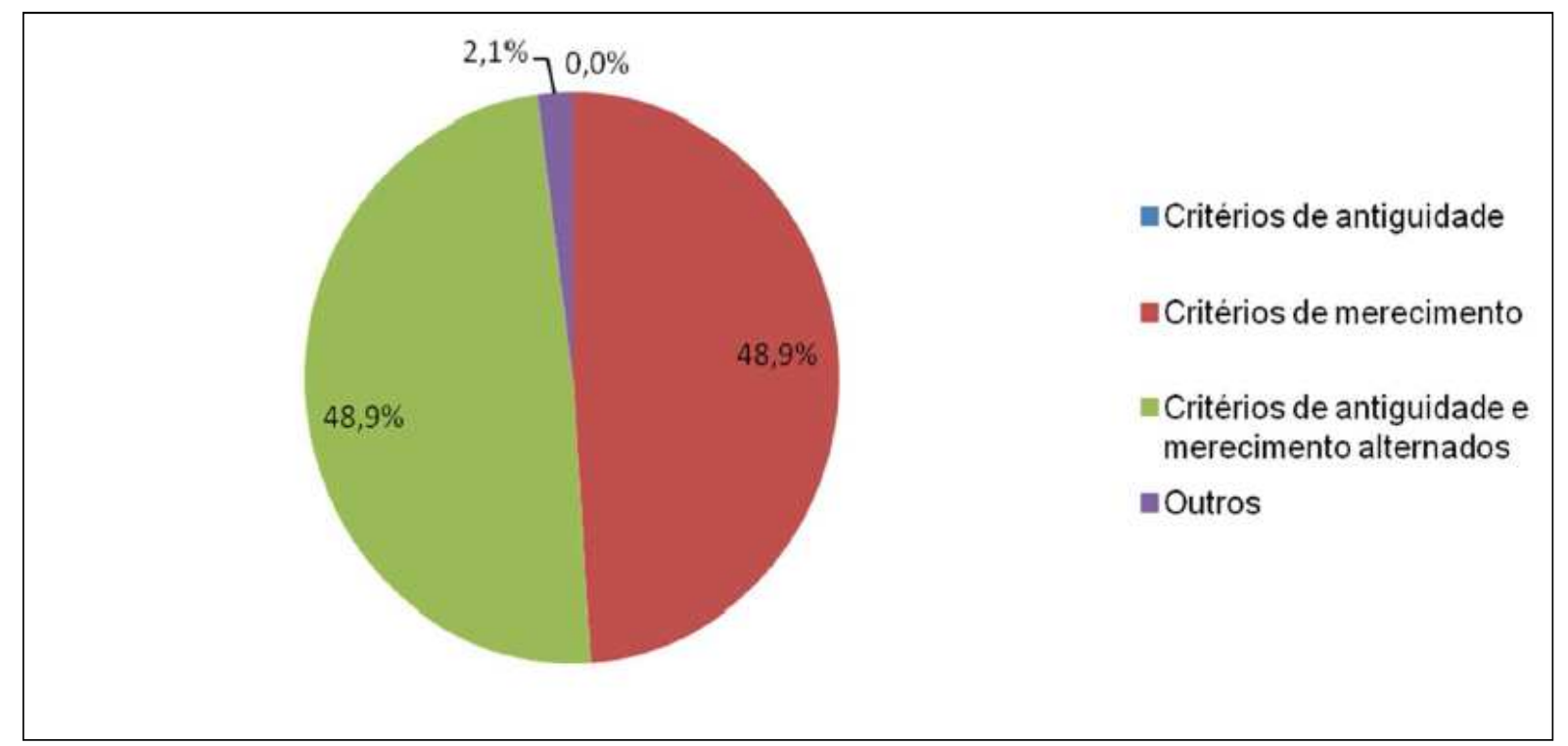

Fonte: Autoria própria.

Além disso, verificou-se que perceber uma gratificação variável e proporcional ao atingimento de metas é considerada como boa motivação para mais da metade dos servidores. Tem-se que $66 \%$ dos analistas, representando 31 pessoas responderam que "é motivante" ou "muito motivante" perceber uma gratificação variável por metas atingidas.

Todas as escolaridades e tempos de serviço estão representados nestes $66 \%$, mostrando capilaridade nas opiniões, o que aponta para a opinião de que gratificação variável e proporcional às metas atingidas não é algo definitivamente rejeitado pela maioria.

Quanto a questão da remuneração, é bastante polêmica na categoria. 19 analistas $(40,4 \%)$ classificam a remuneração como "pouco desmotivante" enquanto outros 17 analistas $(36,2 \%)$ responderam o contrário, que esta é "médio desmotivante". 
Para uma análise mais aprofundada, seria necessário o cruzamento com outros dados, como por exemplo, exercer função gratificada, cargo de chefia, vantagens acumuladas e temporais entre outros fatores que podem compor a remuneração. Como estes dados não foram o alvo da pesquisa, a única análise que pode ser realizada é que a remuneração é uma questão polêmica dentro da categoria.

Um dos grandes males da administração pública brasileira é a distribuição de cargos e funções por critérios de relacionamento pessoal e político. Por desempenhar competências de grande importância e influência dentro da estrutura do governo, e também por possuir um grande número de cargos em comissão, bem superior ao número de analistas, a secretaria sofre grande influência política em seu ambiente interno.

Por meio da pesquisa, verificou-se que 42 analistas $(89,4 \%)$ sentem-se "desmotivados" ou "extremamente desmotivados" com a utilização destes critérios. Ainda, 57,4\% (27 analistas) declararam-se "extremamente desmotivados" com estas situações.

Uma questão levantada, e que ocorre frequentemente em qualquer esfera do poder executivo, é que todo novo governo que assume, uma das suas primeiras medidas é reestruturar a administração, cancelar a maioria dos projetos e andamento que eram da gestão passada, e muitas vezes recomeçar do zero para atingir os mesmo objetivos, só que de forma diferente e desperdiçando os recursos já utilizados.

A avaliação de desempenho individual, realizada anualmente, tem seus critérios definidos na legislação. Apenas nove analistas (19,2\%) consideram os critérios "pouco adequados" ou "nada adequados".

A avaliação utilizada é do tipo 360 o, sendo esta qualificada como a avaliação mais importante por produzir informações vindas de diversas partes, inclusive de superiores e pares. Ser bem avaliado significa ter sua dedicação e seus esforços reconhecidos de maneira formal.

Obter este reconhecimento é "motivante" ou "muito motivante" para 34 analistas (72,3\%). Talvez pelo fato de que seja raro algum servidor ser punido por obter uma avaliação insatisfatória, para outros 13 analistas $(27,7 \%)$ isto é "pouco relevante" ou "nada relevante" ou ainda "não faz diferença".

Em relação ao plano de carreira como um conjunto único, as opiniões são difusas. Para uma melhor análise desta questão, seria necessário abordar outras questões mais específicas do plano de carreira e realizar um cruzamento maior de dados, algo que não é possível de ser realizado neste momento, mas pode ser verificado em uma pesquisa futura.

Uma questão que deveria estar no plano de carreira é a implantação do ciclo de planejamento e gestão, mas este projeto não foi aprovado junto com o novo plano de carreira em 2010. 
A excessiva quantidade de cargos em comissão (CC) na estrutura da SEPLAG é um fator de forte desmotivação para a categoria. Existem dois pontos que podem esclarecer um pouco esta questão. O primeiro é que o CC (muitas vezes sem habilidade profissional para tal) ocupa uma função gratificada ou cargo de chefia no lugar onde poderia estar um analista, provavelmente mais capacitado para a função ou cargo.

Outro ponto é que o quadro de analistas possui 150 vagas e atualmente possui apenas $46 \%$ ocupadas (70 analistas), o que contrasta com o número de CC's (mais de 94) que estão na estrutura da secretaria. Comprovando a desmotivação com este fato, 40 analistas $(85,1 \%)$ sentem-se "desmotivados" ou "extremamente desmotivados" com o número excessivo de cargos em comissão.

Outro cruzamento possível e que corrobora a desmotivação, é o resultado apurado em uma questão apresentada aos respondentes, onde $89,4 \%$ dos analistas desmotivam-se com nomeações por critérios de cunho político ou pessoal.

Em qualquer empresa sempre existem pessoas que não se empenham nas suas funções. Na esfera privada a solução é simples, demissão. Mas e na administração pública, onde infelizmente, alguns servidores se apoiam na garantia de estabilidade e deixam de desempenhar suas funções com o mínimo de presteza, acabando por prejudicar os demais?

De acordo com os resultados, 37 analistas (78,8\%) declararam que ficam desmotivados quando observam este tipo de atitude em alguns colegas. O fato de raramente haver uma punição também contribui para estes resultados obtidos.

De acordo com a revisão da literatura, uma das vantagens da meritocracia é que esta promove maior integração das equipes dentro da organização, em prol de objetivos e metas comuns. No entanto, ao contrário, os dados da pesquisa mostraram que 34 analistas (72,3\%) responderam não concordarem com esta afirmação. Entre as causas para este resultado, foram citadas a necessidade de remodelação dos processos internos e disputas por funções gratificadas.

\section{Considerações finais}

O presente estudo teve como objetivo verificar o grau de motivação dos analistas de planejamento, orçamento e gestão com relação ao plano de carreira meritocrático ao qual estão submetidos.

Os objetivos específicos, sugeridos neste estudo, foram a descrição do histórico da carreira pesquisada, a identificação e análise da percepção dos servidores em 
relação ao sistema de meritocracia, e a identificação de fatores motivadores ou desmotivadores no sistema de meritocracia adotado e no ambiente.

A aceitação dos envolvidos em participar espontaneamente desta pesquisa e a taxa de $67 \%$ no retorno dos questionários pode ser considerada expressiva, visto que a média encontrada na literatura é um retorno por volta de $30 \%$.

Para a realização deste trabalho, as dificuldades encontradas foram a pouca quantidade de material teórico sobre meritocracia na administração pública, bem como algumas falhas detectadas pelo autor no questionário, durante a análise dos dados. Estas deficiências encontradas não invalidam o estudo, tampouco o diminuem, mas se tivessem sido identificadas antes da aplicação do questionário, a análise dos resultados ganharia ainda mais qualidade.

Em relação aos objetivos do trabalho, a apuração do histórico da categoria mostrou que sempre houve dificuldades relacionadas a grande rotatividade de servidores de carreira, o que prejudica a continuidade dos seus processos internos e enfraquece a secretaria politicamente dentro da estrutura administrativa do Estado.

Atualmente, estes problemas estão um pouco diminuídos, muito em função da própria categoria, que se impôs e atua de maneira mais intensa em busca de soluções.

Um fato que corrobora esta afirmação foram as alterações realizadas pelo atual governo na lei que originou o plano de carreira, pressionado pela iminente situação de greve da categoria em julho de 2012 - fato inédito até então provocada pela insatisfação geral com o plano de carreira.

Como observado ao longo deste estudo, o plano de carreira original mostrou-se bastante limitado em suas recompensas e benefícios por um bom desempenho, não motivando de fato, os servidores a buscarem seu melhor. Quanto aos objetivos de identificar e analisar a percepção dos servidores em relação ao sistema da meritocracia foi demonstrado que as mudanças realizadas foram consideradas muito relevantes pela grande maioria dos servidores, mesmo que tenham descaracterizando o projeto inicial.

É possível sugerir que ainda existam 70 analistas na carreira por estas mudanças. Se o plano não tivesse sofrido adequações provavelmente teríamos bem menos do que 70 servidores em uma carreira que possui 150 cargos.

Percebe-se que os servidores não são absolutamente contra a meritocracia, mas que esta não se enquadra no perfil da categoria, muito em função da dificuldade em se mensurar o desempenho das atividades desenvolvidas, como criação de políticas públicas, captação de recursos externos, elaboração do PPA, entre outras. 
Outra percepção dos servidores é que o plano original havia engessado a carreira, dificultando as progressões e distanciando o servidor em início de carreira do final desta em 30 anos.

Já em relação ao último objetivo específico, que pretendeu identificar fatores motivadores e desmotivadores no sistema e no ambiente, podemos citar que a remuneração básica bastante baixa quando comparada a outras carreiras semelhantes, a gratificação de desempenho de 10\% que sobre um salário básico baixo, não é motivação suficiente para muitos.

Mas não é só a remuneração que afeta a motivação. A alteração no interstício, que proporcionou uma movimentação mais célere entre os graus e níveis foi considerada motivante por $89 \%$ dos respondentes e a mudança na forma de reconhecimento do mérito por qualificações acadêmicas, também foi citado por 93,6\% respondentes como motivante.

Outro fator, citado por $85,1 \%$ dos entrevistados e que está causando bastante desmotivação e insatisfação, é o excessivo número de cargos em comissão, utilizados para nomear indivíduos por critérios pessoais e políticos e que, na sua maioria, não possuem qualificação profissional para desempenhar as funções. Além disto, o trabalho de um CC pouco capacitado pode desqualificar a instituição.

Uma questão ligada à anterior é a nomeação para chefias e funções gratificadas sem a utilização de critérios de merecimento. Este fato cria uma luta interna que desagrega os servidores e cria grupos isolados no poder. A grande influência política dentro da instituição também é um problema que desmotiva os servidores.

Uma sugestão para melhorar a motivação é a implantação do ciclo de planejamento e gestão, que valorizaria a carreira tecnicamente e a fortaleceria. $\mathrm{E}$, melhor do que isto, o ciclo iria melhorar a capacidade de planejamento e gestão em muitos órgãos da administração, e estes resultados seriam refletidos em melhores serviços para a sociedade, que é o objetivo mais importante que se deve alcançar.

Acredita-se que o objetivo da pesquisa, de avaliar o grau de motivação com o sistema de meritocracia foi alcançado, e podemos sinalizar que a meritocracia, não é por si só, um fator motivante.

Pelo menos no caso específico que foi estudado ao longo deste trabalho. É necessário muito diálogo entre servidores e governo para que seja implementado um sistema baseado na meritocracia considerado eficiente e satisfatório para todos. E isto não aconteceu com plenitude na SEPLAG no ano de 2010.

Por fim, sugere-se como estudos futuros, a comparação com várias outras carreiras que tenham preceitos meritocráticos, a fim de avaliar suas semelhanças e diferenças, possibilitando conclusões mais amplas sobre o assunto. Também, 
sugere-se a aplicação de pesquisas que possibilitam maior cruzamento de respostas com o objetivo de aperfeiçoar a análise dos dados.

\section{Referências}

Babbie E. Métodos de pesquisa survey. Belo Horizonte: Editora UFMG, 1999.

Barbosa L. Igualdade e meritocracia: A ética do desempenho nas sociedades modernas. 4 a ed. Rio de Janeiro: Editora FVG, $2003 a$.

Barbosa L. Entrevista realizada em 13 de março de 2003, com a antropóloga e Dra. Lívia Barbosa, A Meritocracia no Brasil. 2003b. Disponível na internet em: http://www.talentoseresultados.com/materiac.htm [Acesso em nov. 2012].

Barddal O, Bauer A, Lopes D, Machado D. Implementação de novo modelo de avaliação de desempenho \& recompensa: CASO GE. São Paulo: FGV, 2008. Disponível na internet em: http://www.rij.eng.uerj.br/sponsor/2008/sn08302.pdf [ Acesso em nov. 2012].

Cervo AL, Bervian PA. Metodologia científica: Para uso dos estudantes universitários. 3a ed. São Paulo: McGraw-Hill, 1983.

Dessler G. Administração de recursos humanos. 2a ed. São Paulo: Prentice Hall, 2003.

Duarte G. Dicionário de administração. 2ª ed. Fortaleza: CRA/CE e Realce, 2005.

Fischer AL. O conceito do modelo de gestão de pessoas - Modismo e realidade em gestão de recursos humanos nas empresas brasileiras. In: Dutra JS (Org.). Gestão por competências: Um modelo avançado para o gerenciamento de pessoas. São Paulo: Gente, 2001. p.9-23.

França ACL. Práticas de recursos humanos - PRH: Conceitos, ferramentas e procedimentos. 1ạ ed. São Paulo: Atlas, 2009.

Gil AC. Como elaborar projetos de pesquisa. 3a ed. São Paulo: Atlas, 1991.

Gonçalves CA, Meirelles A de M. Métodos e técnicas de pesquisa social. 5 a ed. São Paulo: Atlas, 1999.

Gonçalves CA, Meirelles A de M. Projetos e relatórios de pesquisa em administração. São Paulo: Atlas, 2004.

Lakatos EM, Marconi M de A. Fundamentos de metodologia científica. 6ạ. ed. São Paulo: Atlas, 2007. 
Malhotra N. Pesquisa de marketing: Uma orientação aplicada. 4 a ed. Porto Alegre: Bookman, 2006.

Silva EL, Menezes EM. (2000) Metodologia da pesquisa e elaboração de dissertação. Programa de Pós-Graduação em Engenharia de Produção, Universidade Federal de Santa Catarina, Florianópolis, 2000.

Sovienski F, Stigar R. Recursos humanos X gestão de pessoas. Biblioteca virtual da Universidade Federal do Rio Grande do Sul. Disponível na internet em: www.eavirtual.ea.ufrgs.br/negcol/index.php?\&cod Nivel=5\&codinstancia Nivel $=10 \&$ userRole $=2$ [ Acesso em nov. 2012].

Zanella LCH. Metodologia de estudo e de pesquisa em administração. Florianópolis: Departamento de Ciências da Administração/UFSC, 2009. 